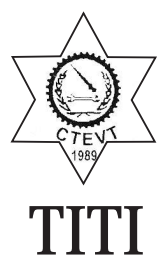

DOI: http://dx.doi.org/10.3126/jtd.v2i0.15433

ISSN: 2392-4578(Online)

\title{
Understanding Gender Neutral language at workplace: Study of TEVT schools of Nepal
}

\author{
Basanti Roshan Pradhan Shrestha \\ Chief, Research and Development Department \\ Training Institute for Technical Instruction (TITI) \\ Sanothimi, Bhaktapur, Nepal \\ Email for correspondence: brs@titi.org.np or brsshrestha@yahoo.com
}

\begin{abstract}
This study tries to understand how female instructors perceive use of gender neutral language in the workplace. Traditionally there had been stratification in male and female on the basis of work and also on the basis of language; but lately, a number of efforts have been made to remove stratification on the basis of gender. Still many reports argue that there is bias on the basis of gender language in the workplaces. The traditionally built stereotype on job roles of males and females given by the society people may not support and go in line with the practice of using gender neutral language. Therefore, this paper had aimed to explore the use of gender neutral language in technical schools of Nepal. To begin the study, eight female instructors from different technical schools of Nepal with different occupations were purposively selected. A case study research design was implied to understand the perception of female instruction with regards to gender neutral language in their work place.
\end{abstract}

Key words: : Gender neutral language, discrimination, instructors and communication

\section{Introduction}

In this modern world, communication plays a vital role in workplace. None of us cannot live without communication; therefore, one can express their ideas and feelings orally or in writing (Drynan, 2011). The same logic can apply everywhere in workplace and organization. The ability to communicate creates healthy work culture and build up the instructors' professionalism. No matter how we speak or what language we use in teaching profession, the profession demands good communication skill for both male and female instructors. Therefore instructors who are involved in teaching profession need to be highly skilled in these areas to excel in their profession.

But in reality, male and female have had trouble communicating effectively since the beginning of time, and it is not just in the workplace (Litosseliti, 
2013). Most of the difficulties in communication are the gender related words due to different statuses of men and women in the society. In fact, such differences have been the topic of debate at home and in organization as well. The gender differences in the language have been caused due to differences in social construct with respect to the gender and age factors (Dong, 2012). Gender differences in communication may cause much frustration and anger between male and female, and this difference is as a result of the socialization and traditional gender roles and social culture of the society (Drynan, 2011). It is thus significant to learn the skills needed to work together in harmony, and practice effective communication where both gender are respected.

With the global change, the society changes; so does the language we use to communicate. The study of language and gender has been an area of interest for over the years. The language we use for addressing each other; the ways in which the both sexes communicate with each other; and the language used to represent gender in society are found to be an interesting area of study with regards to how gender neutral language has been in use in the workplace (OCR, 2015). Therefore, this study mainly focuses on how female instructors perceive the use of gender neutral language in the technical schools of Nepal.

\section{Why Gender Neutral Language ?}

In the past, no matter how much were the women educated, the perception of societies towards female was narrow and the society treated the male as blessed in every aspects of life. Now with the change of time and education provided to females, the working women in our society have been tremendously increasing. So, women are found to have participation everywhere in the society and in the workplace (Wright, 2010).

As we know that language is the one of the tools for the communication but gender bias in communications still exists in the workplace that hinders in the acceptance to women as equal participants. The loss of the focus pronoun and words, and stereotyping words that exclude women in society is still found in workplace communications. Such language discrimination decreases their work performance which also further bars the capability and performance of women. Some language lacks the respect for women that serves to trivialize or demean their accomplishments. Many policy and programme developers bring their own biases to their work, according to their gender, cultures, education and economic status. Knowledge and good intentions can reduce biases, but cannot eliminate them. In language, this equality takes the form of parallel word choices for both men and women, and the elimination of terms that exclude stereotype or demean women.

So to create the healthy working environment, the concept of gender neutral language has been introduced that includes gender neutral language and can bring improvement in verbal and written communication in the workplace. The government also endorses a gender neutral language policy to remove this barrier and supports its commitment to employment equity.

The gender neutral language is neither masculine nor feminine and avoids using gender specific pronunciation such as 'he or she' (Adams, 2015). The purpose of using gender neutral language in speaking and writing is to minimize assumptions about the gender and sex of people (Dong, 2014). Gender-neutral or gender included language or nonsexed language treats both sexes equally and does not indicate one's gender allowing to address people without making gender assumptions (Stevenson, 2014). Using such language in work place assists in creating a safer, more inclusive learning environment. With the increased participation of women in the workplace, one might assume that the barriers to their full participation in getting jobs and winning promotions have been removed. Gender-neutral language can be also used in writing where the gender of a person is considered unimportant but language is considered as important. 


\section{Gender and Language}

The social status and mental state of male and female are different. Due to the traditional role in society, the participation male and female in social activities and their contribution have a great difference which results in the variations of their language. This causes the diversity of the language in male and female (Dong, 2014). The most significant approach on social differences between males and females are dominance, difference and defect.

The dominance approach is a traditional patriarchal approach and believes that men and women inhabit a cultural and linguistic word where power and status are not equally distributed which provides a negative impact of women's language (Nemati \& Bayer, 2007). Due to traditional social status of women, they are responsible for indoor household activities. As they are not exposed to outer world and are dominated by male, manner of speaking is different to men that reflect their subordinate status in society (Litosseliti, 2013). Thus, women's language is marked as powerlessness, shyness, weakness, passive speaking, and expressed through the use of unnecessary qualifiers, which disqualifies women from positions of power and authority. Men dominate and control women both with interactions and with the language system itself (Merchant, 2012).

According to difference in approach, as men and women belong to different sociolinguistic subculture, they live in different beliefs they have developed different linguistic behaviors (Abbas, 2010). This results in the varying communicative styles of male and female. Although male and female live in the same society, they have different life experienced since their childhoods. The reason is that they have learnt different linguistic behavior and style based on the sex when they interact with peers or elders (Hamdan \& Hamdan, 2013).

In Deficit approach, women's way of speaking is deficit in comparison to that of men whether by nature or nurture (Carmeron, 1998). Women use language in a way which reflects their subordinate position in society, and men do in a way which reflects their power. In deficit approach, women face hindrances as language users. Women have limited vocabulary that reflects that women's language style which is deficient, lacking in authority and assertiveness (Simpson, 2011). Females' language has a subservient status considering it as deficient, unconventional and even incomplete by comparison to males' normative language. Form the childhood girls are taught how to use female language so that they are socialized to use lady like language (Hamdan \& Hamdan, 2013).

These psychological gender differences in communication styles influences strategies to create stereotypical role for men and women in the workplace (Merchant, 2012). Therefore, gender differences in communication styles in workplace cause a gap and conflict between men and women. Some of these stereotypes have negative effects on women's behaviors and perceptions of females in the workplace. These have effect on them both in society and their workplace. Hence, in this respect, use of gender neutral language has come into light especially in workplace and has started to be used by both male and female. In this line, I have put forward the research question stated below.

\section{Research question}

- How do female instructors perceive about gender neutral language?

\section{Case study research design}

The case study as Yin (2003) believes fall under constructivist paradigm. Researching on the use of gender neutral language in TEVT schools of Nepal fits here as it focuses to answer process questions (Yin, 2003). A case study is a specific instance that is frequently designed to study more general principles and practices, and is the study of an instance in action (Creswell, 2008). The single instance is of a bounded system; for example: a teacher, a class, a school or a community. It provides a unique example of real people in real situations, enabling readers to understand ideas more clearly 
than simply by presenting them with abstract theories.

The strength of qualitative case studies lies on researcher as key instrument and multiple sources of information along with several others characteristics. Qualitative researches especially the case study research design may shift tool and even focus to the problem as study undergoes to the issue. "The research process for qualitative researchers is emergent" (Creswell, 2008). The issue of seeking use of gender neutral language practice and replication possibilities can be best explored with more flexible research methods. This builds a ground for selection of case study approach for the study. As no logical subunits can be defined in this study, TEVT teachers under council for technical education and vocational training (CTEVT), remains the single unit of study. "The holistic design is advantageous when no logical subunits can be identified or when relevant theory underlying the case study is itself of a holistic in nature" (Yin, 2003).

The eight female instructors were selected randomly from the seven different technical schools of Nepal. The instructors were interviewed individually and their interviews were recorded for the data transcription. The findings of the study are based on the response and experience of female instructors within their schools.

\section{Female instructor perception towards the use of gender neutral language}

The female instructors were unknown and unaware about the gender neutral language. One instructor had few knowledge of the gender neutral language but had not tried to implement neutral language in the workplace. Some of them had heard the word neutral language but did not know the concept of gender neutral language in the workplace. Some of them were found to be using the neutral words such as students; teachers; persons in the school, without unknowing the concept of gender neutral language.

The study shows that the masculine and feminine words are popular and familiar in the technical schools. The lexical words 'madam' and 'miss' were found to be used for female instructors to convey the information. In the same way, the lexical word 'sir' was being used for the male instructors to convey the information in formal working environment. Similarly, the gender inclusive language like 'brother', 'sister', 'uncle' have been used to flow the communication in the school as stated by Horvath et al (2016). They think that these words are the formal and official language to address the staff of the organization.

Though, 'Madam' and 'Miss' were commonly words for females, the perception of female instructors is that is the word 'Madam' was superior and humble words for the female. So, most of the female instructors preferred to be addressed by 'Madam'. The word 'Miss' was found to be used for the juniors and inexperienced instructors. So it was found that they did not like to be called by 'Miss' due to the feeling of being dominated. While doing the discussion, they also said that in some cases, female tried to dominate female because of jealously. So, female tried to grab the opportunity from female and they did not want to acknowledge others' performance. So they tried to express the jealously through verbal discrimination and biased language to dominate the female colleagues.

\section{Gender discrimination: female instructor voice}

When discussed about the gender discrimination word or pronoun, they expressed that formally there were no such discrimination word has been observed in the school but informally behavior of the male and the type of biased language and the dominating behavior has been observed and noticed in meetings and other official task. The female instructors felt less included, evaluated the work environment less positively and less job based competence than did men, regardless of the type of language that was used in the job description.

In meetings, no such bias was observed and seems that everyone treated equally. But in discussion and 
in communication, masculine words and pronouns were used frequently. In decision making, the voice of the female seemed to disagree which can clearly be observed by the body language and gesture of the male instructors and other female staff of the school. The body language of male was found to be indicating negative feelings towards female's voice and opinions. They assured that this is reality occurring in the school and not a misinterpretation. This may become an issue in workplace where the female instructors feeling and opinion are neglected (Merchant 2012). That would lead to the demotivation, frustration and work proficiency slowdown in the workplace. This clearly shows that women's opinions were not being valued. Instructors said that most of their input was neither viewed with positive remarks, nor were acknowledged during the meetings. Others shared that their views and opinions were not being taken seriously and were given stereotypically inclined tasks despite their qualifications. Disrespectful language and misgendering can make it difficult for female instructors to participate fully in meetings. Usually male instructors use words without noticing and do not realize how others feel and may get upset.

\section{Discussion and Conclusion}

The study shows that female instructors who work in traditionally male dominated occupations faced more gender discrimination in verbal language than females who work in occupations traditionally assigned for females (Martin \& Barnald, 2013). An organization's success depends upon its ability to embrace diversity and realize the benefits. Therefore, organization itself should actively assess the handling of workplace diversity issues, develop and implement plans, and accept the innovative changes that focus towards the organizational and staff development. Languages vary in the number of linguistic elements that need to be changed for creating neutral language and the nature of the changes effects of ease of implementation of gender neutral language. But in reality, traditional, social and gender roles are hard to accept the change in gender and language in society and workplace. Once the organization acts as catalyst to bring changes to demonstrate the neutral language, we can bring changes in our workplace, and changes to women's social status in the society. Organizations need to introduce formal policies to create an environment for women entering and remaining in male-dominated occupations that hinder the biased language. Many schools and organizations have official policies and rules that support the use of gender-neutral language in the workplace. In some cases, laws exist to enforce the use of gender-neutral language in certain situations, such as job advertisements (Stout, 2009). Different authorities have presented guidelines on when and how to use gender-neutral language. The staff of the organization makes a habit of using gender inclusive language that does not discriminate the all staff on the basis of gender identity and male dominated occupations.

The development of policies and awareness programs is deemed necessary to increase of social communication activities within schools; decrease gender biased language; and increase the language similarities between males and females. It will help to understand the similarities and differences of language use between males and females as stated by Dong (2014). It also contributes to neutral communication and makes people use it exactly in social life. At the same time, it will benefit the social culture studies and promote to predict the development trend of language and make policies. Besides, it has positive effect on the social spiritual civilization development of society.

\section{References}

Abbas, M. M. (2010). Lexical Analysis of Gender and Language Theories. Babillion-Hilla: Iraq. Retrieved from www.uobabylon.edu.iq/ publications/humanities_edition $2 /$ humanities_ed2_2.doc

Adams, P. (2015). Gender neutral language. Singapore: Sage publication.

Cameron, A. (1998). The First Feminist Critique of Language: A Reader. London: Psychology Press 
Creswell, J. W. (2008). Qualitative inquiry and research design. New Delhi: Sage.

Dong, J. Y. (2014). Study on gender differences in language under the sociolinguistics. Canadian Social Science, 10 (3), 92-96. doi: 10.3968/4602

Drynan, L. (2011). Communication Clash: Gender and General Effects on Communication in the Workplace. Retrieved from http://www.amcto.com/imis15/Documents/ Leslie............\%20Communication.pdf

Hamdan, S. M. \& Hamdan, J. M. (2013), Authors' perceptions of author's gender: A myth or a truth? Asian social science 10 (10), 67-83. doi: 10.5539/ass.v10n10p41

Horvath , L. K., Merkel E. F., Maass, A., \& Sczesny S. (2016). Does Gender-Fair Language Pay Off? The Social Perception of Professions from a Cross-Linguistic Perspective. Frontiers in psychology 1(1) 6-12, doi: 10.3389/ fpsyg.2015.02018

Litosseliti, L. (2013). Gender and Language Theory and Practice. London: Routledge

Martin, P., \& Barnard, A. (2013). The experience of women in male-dominated occupations: A constructivist grounded theory inquiry. SA Journal Of Industrial Psychology, 39(2). 19-26 doi:10.4102/sajip.v39i2.1099

Merchant, K. (2012). How Men And Women Differ: Gender Difference in Communication Styles, Influence Tactics, and Leadership Styles. Claremont Colleges, CMC senior theses.Retrieved from http://scholarship.clarem ont.edu/cgi/viewcontent.cgi article $=1521 \&$ context $=$ cmc_theses

Nemati, A. \& Bayer, J. M. (2007). Gender Differences in the Use of Linguistic Forms in the Speech of Men and Women: A Comparative Study of
Persian and English. IOSR journal of humanities and social sciences 13 (3) 63-79. Retrieved from h t t p : / / w w w .ios rjournals.org/ios r jhss/papers/Vol13-issue3/I01336779.pdf?id=3396

OCR. (2015). English Guide, and Theme: Gender and Language.. Cambridge: Oxford Cambridge and RSA examination. Retrieved from http://www.ocr.org.uk/Images/231748-language and-gender-delivery-guide.pdf

Simpson, J. (2011). The Routledge Handbook of Applied Linguistics. London: Routledge

Stevenson, J. (2014). Gender neutral language at workplace. New York: Sage publication.

Stout, J. G. (2009). When he doesn't mean you: Gender-exclusive language as a form of subtle ostracism. Published masters theses submitted to University of Massachusetts Amherst in partial fulfillment for the requirement of masters of science. Retrieved from http://scholarworks .umass.edu/cgi/viewcontent.cgi? article= $1288 \&$ context $=$ theses

Wright, J. (2010). Gender inclusive practices within the primary classroom. Published masters theses submitted to University of Massachusetts Amherst in partial fulfillment for the requirement of masters of education, RMIT University Australia. Retrieved from https://researchbank. rmit.edu.au/eserv/rmit:9478/Wight.pdf

Yin, R. K. (2003). Case study research design (3rd ed.). New Delhi, Sage. 